\title{
Estudio estratigráfico de enlucidos
}

Fátima Bermúdez-Coronel Ga. de Vinuesa Ma. Paz Ruiz del Portal Ruiz-Granados

Restauradoras

\section{Introducción}

Para aproximarse al conocimiento de las características constructivas de los monumentos históricos existen diferentes métodos de estudio. Según Roberto Parenti, en la aplicación de la estratigrafía para el análisis de edificios históricos se diferencian cuatro procedimientos: el método de estudio archivístico basado en documentos o bibliografía existente; el llamado naturalista, consistente en el empleo de análisis técnico-científicos; el de confrontación entre la documentación existente y el estudio de restos encontrados; y un cuarto método, denominado de lectura de las pruebas materiales, en el que se estudian los restos de las sucesivas intervenciones, que se han ido superponiendo o estratificando en el monumento.

En este último método de lectura nos hemos basado para el estudio estratigráfico de las pinturas decorativas que se han ido superponiendo a lo largo de la historia de este edificio, para intentar comprender o identificar los procesos, transformaciones y modificaciones que ha sufrido. Este estudio se acompaña de diferentes fichas, describiendo las unidades estratigráficas y las muestras extraídas (figura I). Entendemos este análisis como un dato fundamental, a la hora de adoptar un criterio en la restauración y conservación de la puerta y para interpretar los resultados históricos y técnicos.

\section{Estudios estratigráficos}

El objetivo de este estudio de enlucidos es identificar, analizar y valorar los distintos estratos decorativos que existen en las diferentes zonas de la Puerta

\begin{tabular}{|c|c|c|}
\hline \multicolumn{3}{|c|}{ FICHA DE EXTRACCIÓN DE MUESTRAS } \\
\hline \multicolumn{2}{|c|}{ TÍTULO U OBJETO: } & Enfoscado con bicromía, situado en la torre sur. \\
\hline \multicolumn{2}{|c|}{ CRONOLOGÍA: } & Siglos XVII-XVIII. \\
\hline \multicolumn{2}{|c|}{ MATERIA/ TÉCNICA DE EJECUCIÓN: } & Mortero compuesto de cuarzo y calcita. \\
\hline \multicolumn{2}{|c|}{ FECHA DE EXTRACCIÓN: } & 23 y 26 de abril de 1999. \\
\hline \multicolumn{2}{|c|}{ LUGAR DE LA EXTRACCIÓN: } & Torre sur, paramentos sudoeste. \\
\hline \multicolumn{2}{|c|}{ MEDIOS UTILIZADO: } & Mecánicamente. \\
\hline \multicolumn{2}{|l|}{ PROYECTO: } & Restauración de la Puerta de Córdoba de Carmona (Sevilla). \\
\hline \multicolumn{3}{|c|}{ N MUESTRA LOCALIZACIÓN / DESCRIPCIÓN } \\
\hline 1 & \multicolumn{2}{|c|}{$\begin{array}{l}\text { Paramento sudoeste de la torre sur. Enlucido decorado en ocre, sobre mortero } \\
\text { de grano grueso. }\end{array}$} \\
\hline 2 & \multicolumn{2}{|c|}{$\begin{array}{l}\text { Paramento sudoeste de la torre sur. Enlucido decorado en almagra, sobre mortero } \\
\text { de grano grueso. }\end{array}$} \\
\hline 3 & \multicolumn{2}{|c|}{$\begin{array}{l}\text { Paramento sudoeste de la torre sur. Enlucido decorado en almagra, sobre otro enlucido } \\
\text { del mismo color, ambos sobre un mortero de grano grueso. }\end{array}$} \\
\hline
\end{tabular}


de Córdoba. Esta información nos permite conocer la historia material de la obra, sus usos, adaptaciones, restauraciones anteriores, gustos de las distintas épocas, etc. Y para ello necesitamos determinar:

- Número de policromías.

- Número de estratos de cada policromía.

- Localización y extensión de ellas.

- Tipo de decoraciones.

- Características técnicas de las policromías.

- Estado de conservación.

En un examen preliminar se estudiaron los diferentes elementos de la Puerta para determinar qué zonas eran susceptibles de estudio estratigráfico. La elección vino determinada por el mayor número de informa- ción en un mismo espacio, la simetría del monumento, la accesibilidad y la repetición de la secuencia.

Se han realizado 31 catas estratigráficas que nos han permitido observar las distintas capas subyacentes y obtener información de la decoración en los diferentes elementos arquitectónicos del edificio: columnas, paramentos, cornisas, bóvedas, etc. Dada la poca extensión de estratos decorativos detectados al inicio del trabajo, las ventanas de estudio o catas estratigráficas se ejecutaron según un plan de registro y con distintas dimensiones, desde 2' $5 \mathrm{~cm}$ a $10 \mathrm{~cm}$ en función del tamaño de la superficie a estudiar. Aquí sólo se muestran las más significativas, ya que las secuencias estratigráficas se repiten en diversos elementos arquitectónicos.

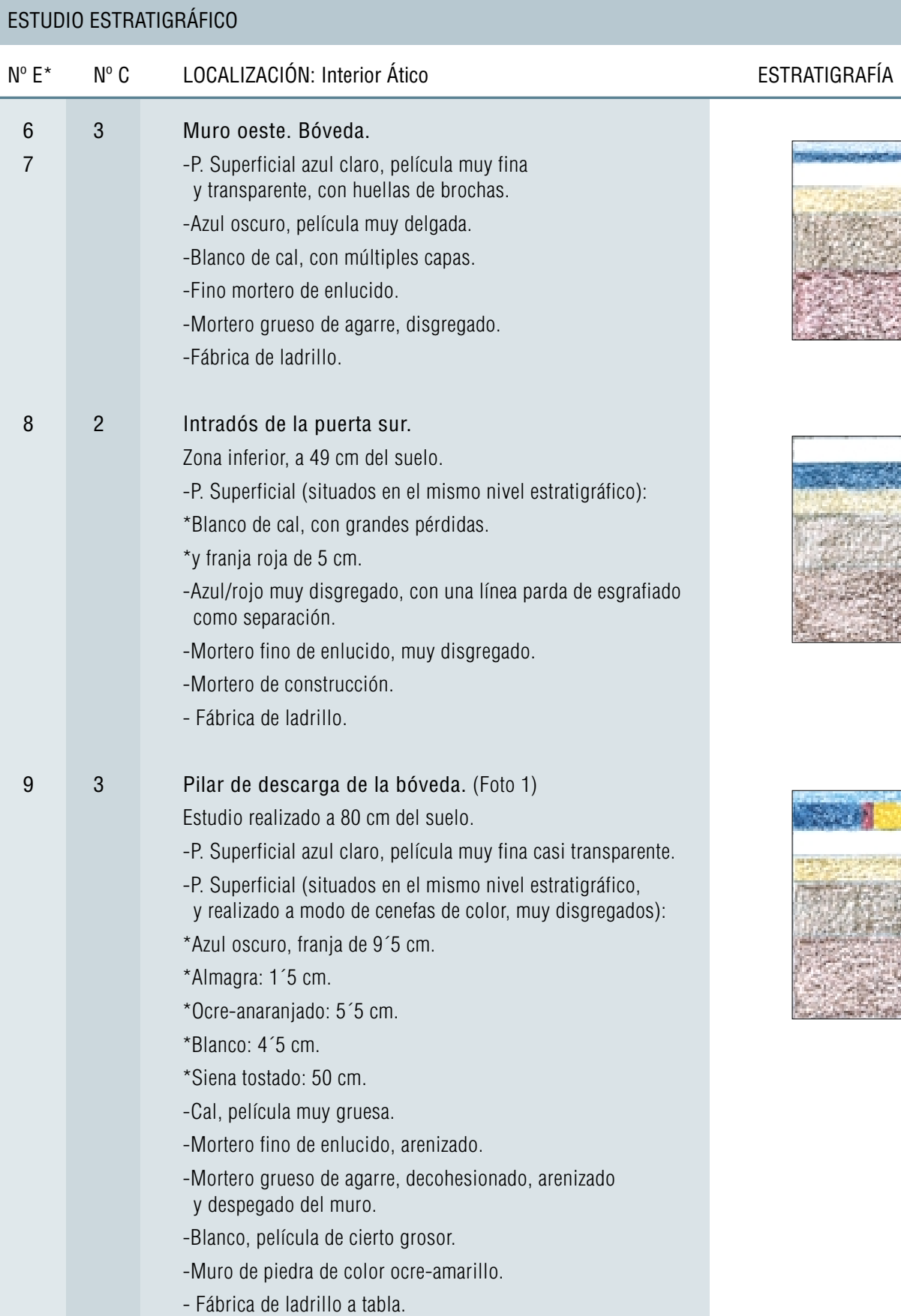



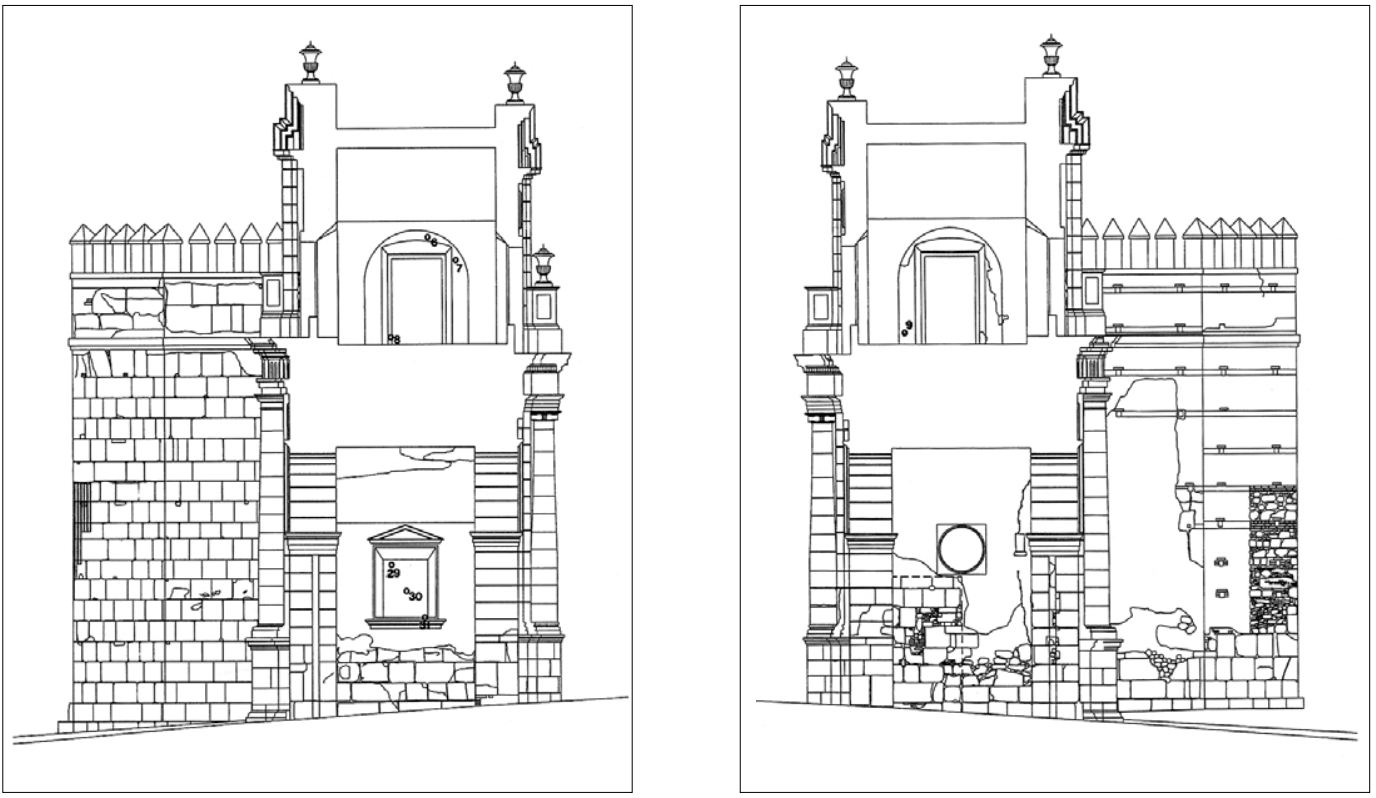

Foto 1. Secuencia de la película superficial situada en el pilar de descarga de la bóveda.

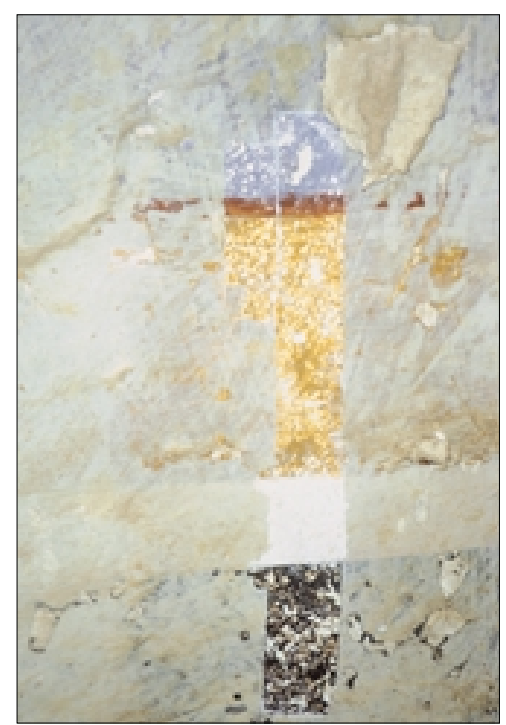




\begin{tabular}{|c|c|c|c|}
\hline \multicolumn{4}{|c|}{ ESTUDIO ESTRATIGRÁFICO } \\
\hline$N^{0} E$ & $\mathrm{~N}^{\circ} \mathrm{C}$ & LOCALIZACIÓN: Fachadas este y oeste & ESTRATIGRAFÍA \\
\hline \multirow{5}{*}{$\begin{array}{l}14 \\
26\end{array}$} & \multirow[t]{5}{*}{1} & Cornisas superiores. (Foto 2) & \multirow{5}{*}{ 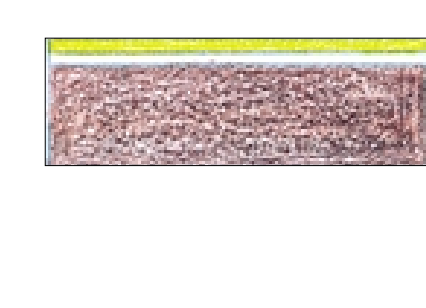 } \\
\hline & & Ladrillo aplantillado u ornamental. & \\
\hline & & $\begin{array}{l}\text {-P. Superficial: amarillo, estrato muy fino, casi transparente bien } \\
\text { cohesionado, fuertemente adherido al estrato anterior, } \\
\text { reproduciendo craquelado. }\end{array}$ & \\
\hline & & $\begin{array}{l}\text {-Blanco, poco estable, muy adherido al estrato anterior. } \\
\text { Presenta fino cuarteado. }\end{array}$ & \\
\hline & & -Ladrillo tallado. & \\
\hline \multirow{8}{*}{$\begin{array}{l}15 \\
27\end{array}$} & \multirow[t]{8}{*}{2} & Frontones superiores. & \multirow{8}{*}{ 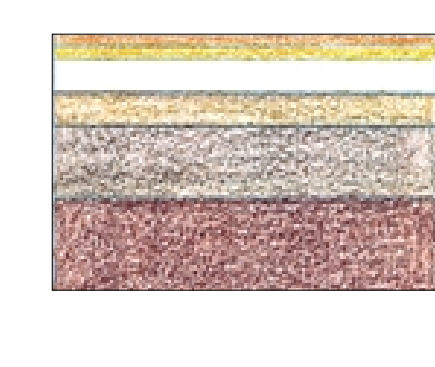 } \\
\hline & & Muro de ladrillo. & \\
\hline & & -P. Superficial: ocre, opaco, mal adherido al estrato anterior. & \\
\hline & & & \\
\hline & & -Blanco, película gruesa. & \\
\hline & & -Mortero de enlucido, disgregado. & \\
\hline & & -Mortero grueso de agarre. Arenizado. & \\
\hline & & -Muro de ladrillo. & \\
\hline \multirow[t]{5}{*}{21} & \multirow[t]{5}{*}{2} & Fachada este. & \\
\hline & & Dintel del arco. & \\
\hline & & Muro de ladrillo. & \\
\hline & & Repite las secuencias estratigráficas 15 y 27. & \\
\hline & & $\begin{array}{l}\text { NOTA: Las portadas Este y Oeste se registran en una misma } \\
\text { ficha debido a la repetición de sus secuencias estratigráficas. }\end{array}$ & \\
\hline
\end{tabular}

\section{ESTUDIO ESTRATIGRÁFICO}

NN E N $\quad N^{\circ} \mathrm{C} \quad$ LOCALIZACIÓN: Torre Sur.

\section{ESTRATIGRAFÍA}

192 Paramento sudeste. (Foto 3)

-P. Superficial: ocre, estrato muy fino, brillante y de textura lisa. Mal cohesionado, fuertemente adherido al estrato anterior. Presenta grandes pérdidas.

-Mortero, película lisa, fina y porosa. Presenta grandes pérdidas. -Ocre, película muy fina y lisa.

-Mortero de enlucido, blanquecino y muy fino.

-Mortero de agarre, de grano muy grueso y con cascotes de ladrillo. Disgregado y arenizado. Mal adherido.

-Muro de piedra.

202 Paramento sudeste.

-P. Superficial: Almagra, estrato muy fino, brillante y de textura lisa. Mal cohesionado, fuertemente adherido al estrato anterior. Presenta grandes pérdidas.

-Mortero, película lisa, fina y porosa. Presenta grandes pérdidas. -Almagra, película muy fina y lisa.

-Mortero de enlucido, blanquecino y muy fino.

- Mortero de agarre, de grano muy grueso y con cascotes de ladrillo. Disgregado y arenizado. Mal adherido. -Muro de piedra.

2211 Paramento sudeste.

-P. Superficial: almagra, película fina y lisa.

Presenta grandes pérdidas

-Mortero de enlucido, blanquecino y fino, con grandes pérdidas.

-Mortero de agarre, de grano muy grueso y con cascotes de ladrillo. Disgregado y arenizado. Mal adherido.

-Muro de piedra.

La misma secuencia estratigráfica se repite con un solo estrato en zonas donde encontramos ocre.
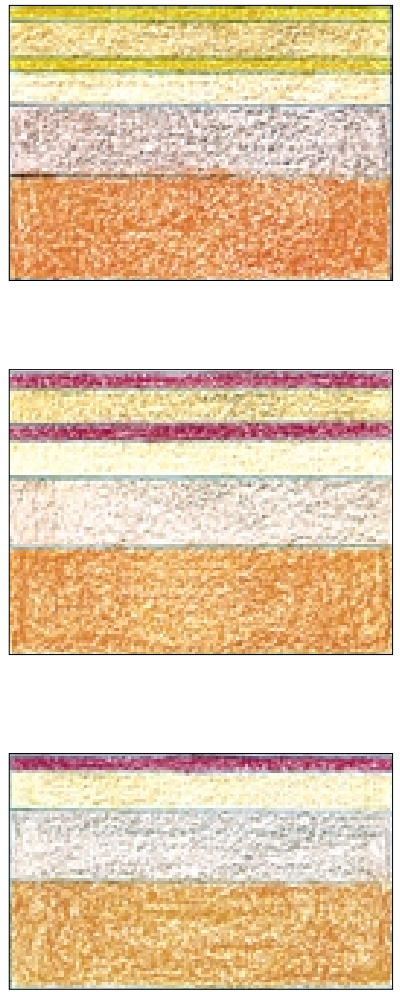
Fig. 3 Portada este $\left(n^{\circ}\right.$ E 14,15 y 21$)$

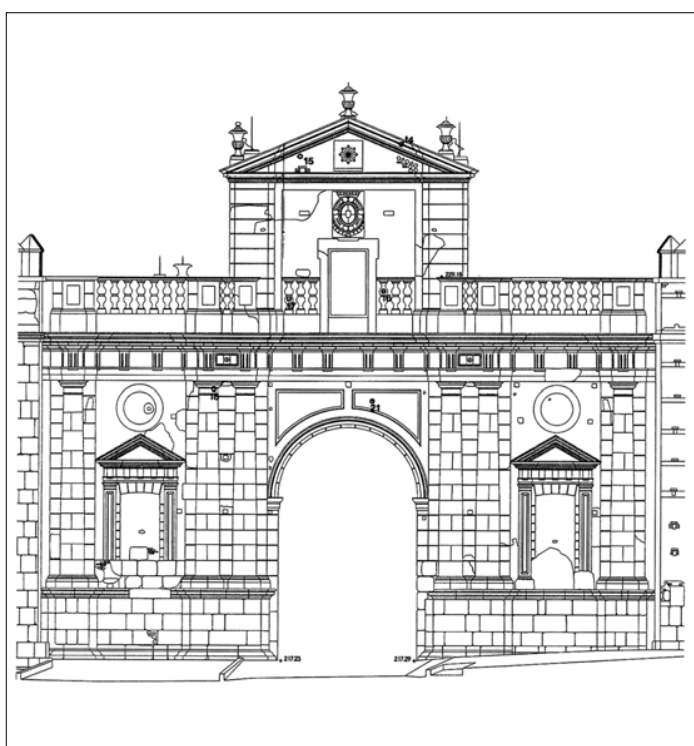

Fig. 4 Portada oeste ( $n^{0}$ E 26 y 27$)$

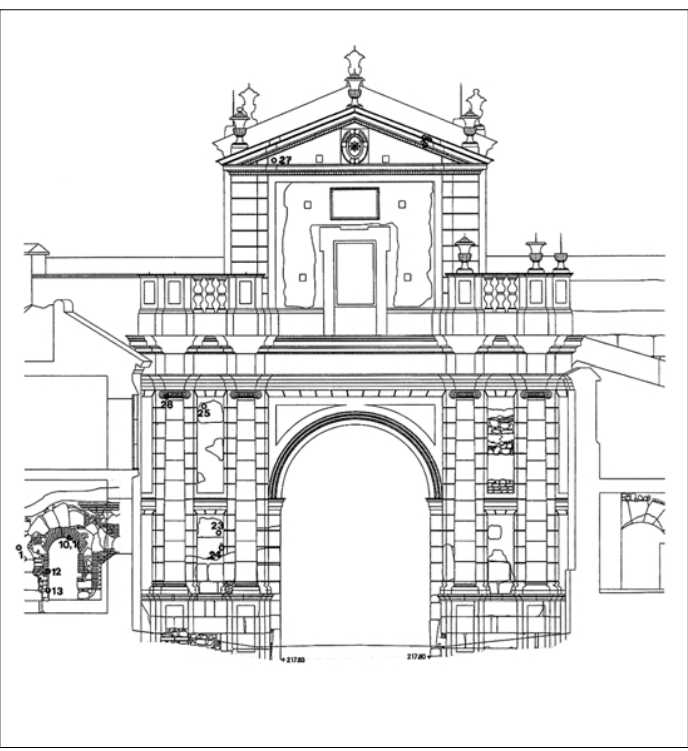

Foto 2. Detalle de cornisa en la fachada este

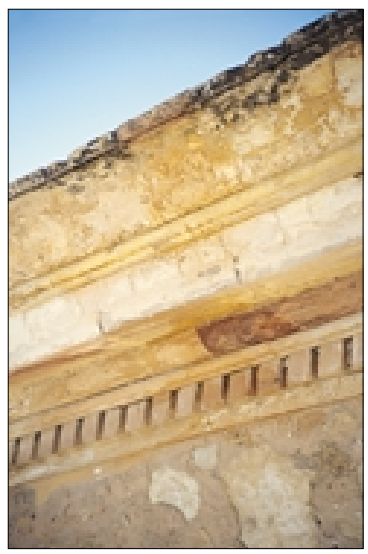

Fig. 5 Torre sur $\left(n^{0} \mathrm{E} 19,20\right.$ y 21$)$

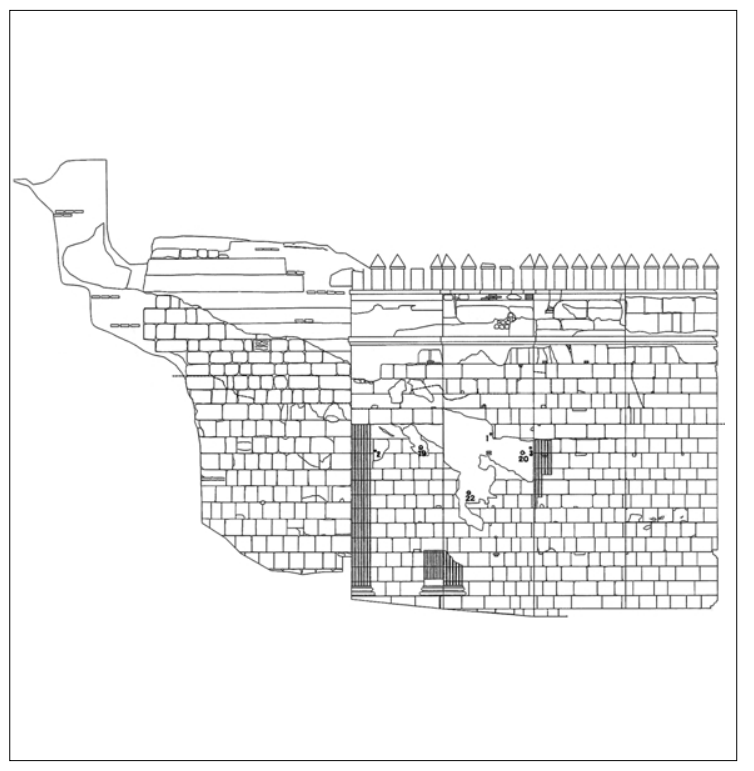

Foto 3. Morteros en la torre sur, paramento sudoeste

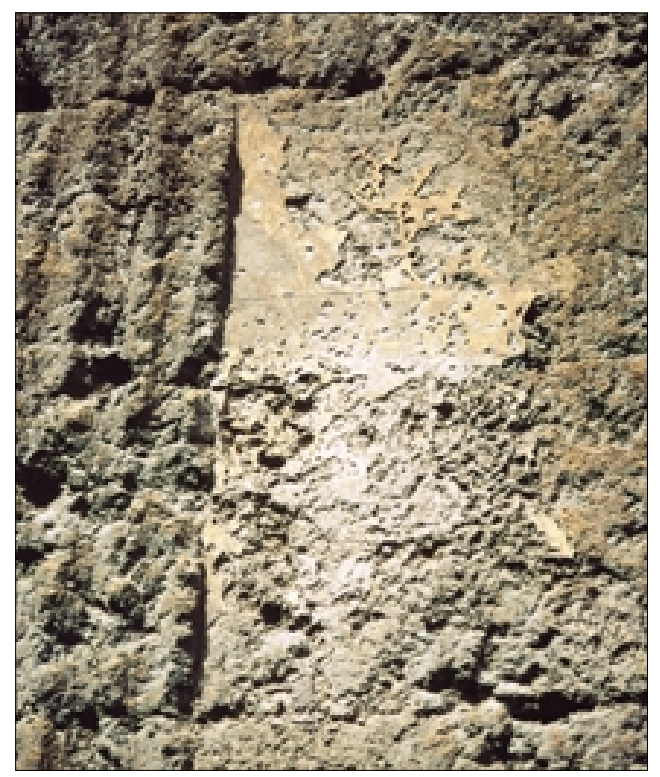




\section{Porcentaje de decoración pictórica}

Los restos de pinturas halladas en la Puerta de Córdoba son mínimos, lo que nos ha imposibilitado la realización de un estudio de correspondencia de capas pictóricas. No obstante, se han recogido datos de las diferentes decoraciones conservadas en el monumento, valorando la proporción de las pinturas existentes en:

\section{Fachada este}

- Cornisas: 30\% de decoración amarilla.

- Cuerpo de ático: $18 \%$ de decoración ocre.

- Balaustrada: 5\% de decoración ocre.

- Entablamento: 5\% de decoración ocre.

- Columnas: $2 \%$ situado en los capiteles, de pintura ocre directamente sobre la piedra.

- Vanos cegados: $0 \%$.

- Zócalo de piedra: 0\%.

\section{Fachada oeste}

- Cornisas: 30\% de pintura amarilla.

- Cuerpo de ático: 5 \% de pintura ocre.

- Columnas: $2 \%$ en los capiteles.

- Vano izquierda: 25\% de color rojizo.

- Vano derecho: 0\%.

- Zócalo de piedra: 0\%.

\section{Interior ático}

- $80 \%$ de pintura decorativa formando zócalo de varios colores subyacentes a una capa azul celeste.

\section{Torre norte}

- 20\% localizado únicamente en el paramento noroeste adosado a vivienda.

Torre sur

- $5 \%$ de mortero muy disgregado bicromático ocre y almagra.

\section{Pasaje norte}

- $40 \%$ fundamentalmente de capas de cal exceptuando la zona baja hasta el poyete donde encontramos azules y almagras.

\section{Estado de conservación}

Los muros de la Puerta de Córdoba, formados por de sillares de piedra y fábrica de ladrillo, se encuentran revestidos con morteros de enlucido predomi- nando el color ocre amarillo, aunque también se aprecian intervenciones con una clara intención decorativa, simulando zócalos y/o sillares, en los que se han utilizado una gama más amplia con azules, rojos, ocres, tierras tostadas y blancos.

Para poder definir el estado de conservación de dichas pinturas hay que tener en cuenta los escasos restos encontrados en el momento de la realización del estudio. La información obtenida es parcial, debido al avanzado estado de deterioro, con pérdida de material constructivo y decorativo, y con fenómenos de alveolización, arenización, fisuras y desplacados, que repercuten de manera directa sobre la conservación de la capa pictórica que la decora. Las patologías más importantes se localizan en:

- Zonas con humedad donde los morteros se encuentran muy decohesionados, con peligro de pérdida del estrato de color.

- Disgregación de los pigmentos en la superficie pictórica.

- Falta de cohesión entre el color, enlucido y mortero; por lo que el estado de conservación del conjunto estratigráfico es malo.

- Fino cuarteado en la base de color blanco y pintura amarilla subyacente encontrado en los ladrillos aplantillados utilizados en cornisas.

- Zonas de intervenciones con parcheado de enlucido, realizado con materiales inadecuados.

\section{Conclusiones}

Los monumentos histórico-artísticos evolucionan continuamente a lo largo de su historia modificando sus aspectos primitivos e incluso ocultando sus trazas originales. La finalidad del estudio estratigráfico, aplicado a las capas cromáticas, es establecer las secuencias decorativas, calcular los porcentajes y estudiar el estado de conservación. Todo esto es necesario a la hora de definir y aplicar una propuesta de intervención, en este caso sobre los acabados y la posible decoración del monumento.

En las dos portadas se repite la misma secuencia estratigráfica de manera constante, observando la misma decoración en la utilización del ocre y del amarillo, cambiando únicamente el soporte: piedra, fabrica de ladrillo enfoscado y ladrillo ornamental. En la portada oeste, en los vanos situados a la izquierda del arco, encontramos fracciones de color que no se repiten en ninguna otra zona (almagra y blanco).

En la torre sur existe información suficiente sobre la decoración esgrafiada con alternancia de dos tonos, ocre y almagra formando sillares. En la torre norte no queda restos de color, salvo algunos vestigios de mortero muy disgregado que sí conservan la huella del esgrafiado. 
En el interior del ático, subyacente a una capa uniforme de azul verdoso, hallamos un zócalo de 0,6I m. de altura con cenefas de varios colores. Esta decoración no tiene calidad ni en sus materiales ni en el aspecto técnico.

Por último encontramos restos de color en el pasaje norte, cubiertos por sucesivas capas de cal que ocultan una decoración en almagra (con el pigmento muy disgregado), y una franja a la altura del adelgazamiento del muro de color azul.

La información obtenida a partir de los escasos restos encontrados en los distintos paramentos no nos permite una interpretación exacta sobre el devenir en la decoración del edificio; los fragmentos de color, situados en las torres norte y sur, pasaje norte, y vanos de la fachada oeste se encuentran aislados. Sin embargo hemos podido definir dos situaciones claramente diferenciadas: en primer lugar la existencia de una decoración repetida en las secuencias, con un tono predominante ocre, -torres y fachadas-, y en segundo lugar una diferencia de color con intencionalidad decorativa y oculta por una o varias capas de cal, localizadas en el interior del ático, el pasaje norte y en el paramento noreste de la torre norte.

En definitiva, la Puerta de Córdoba ha estado decorada en ocre y amarillo en sus dos portadas, pudiendo combinar los vanos en blanco, ocre y almagra. Las torres creemos que únicamente han tenido una decoración esgrafiada reproduciendo sillares. Y en el interior del monumento es donde se ha encontrado decoración ornamental más elaborada aunque reciente, con predominio de los tonos azules, ocres y almagras.

\section{Bibliografía}

GARCÍA RAMOS, R. Examen material de la obra de arte. La correspondencia de policromías. En Boletín PH, n 12, 1995, p: 52-57.

GONZÁLEZ LÓPEZ, Ma J. Metodología de estudio de correspondencia de capas policromas aplicada al conocimiento de la escultura en madera policromada. En Boletín PH, nº 8., 1994, p: $10-13$.

OJEDA CALVO, REYES, TABALES R. MIGUEL A. La investigación arqueológica en Bienes Inmuebles. Metodología aplicada en la Puerta de Córdoba de Carmona. En Boletín PH n 15, 1996, p: $4 \mid-52$.
PARENTI., R. La aplicación del método estratigráfico para el análisis de monumentos. En Patrimonio y Ciudad. Reflexión sobre centros históricos. Consejería de Cultura, Junta de Andalucía. Cuaderno V IAPH., 1994., p:58-66.

TEJEDOR CABRERA, ANTONIO. El proyecto de restauración de la Puerta de Córdoba en Carmona. En Boletín PH n²2, 1998, p: 50-66. 